\title{
PROPERTIES OF GENERALIZED SHARP HÖLDER'S INEQUALITIES
}

\section{JiNG-FENG TIAN AND MING-Hu HA}

Abstract. Hölder's inequality and its various refinements are playing very important in mathematical analysis. In this paper, we give some new properties of generalized sharp Hölder's inequalities.

Mathematics subject classification (2010): 26D15, 26D10.

Keywords and phrases: Hölder's inequality, generalized Hölder's inequality, property.

\section{REFERENCES}

[1] S. Abramovich, J. PeČarić And S. VARošAnec, Continuous sharpening of Hölder's and Minkowski's inequalities, Math. Inequal. Appl. 8, 2 (2005), 179-190.

[2] P. ChunaEV, Hölder and Minkowski type inequalities with alternating signs, J. Math. Inequal. 9, 1 (2015), 61-71.

[3] G. Hardy, J. E. Littlewood, G. Pólya, Inequalities, second ed., Cambridge University Press, UK, 1952.

[4] K. Hu, On an inequality and its applications, Sci. Sinica 24, (1981), 1047-1055.

[5] K. HU, On an inequality and its applications, J. Jiangxi Norm. Univ. 18, 4 (1994), 330-333.

[6] E. G. KwON, J. E. BAE, On a refined Hölder's inequality, J. Math. Inequal. Preprint.

[7] J. Matkows KI, A converse of the Hölder inequality theorem, Math. Inequal. Appl. 12, 1 (2009), $21-32$.

[8] L. Nikolova AND S. VARošAnec, Refinements of Hölder's inequality derived from functions $\psi_{p, q, \lambda}$ and $\phi_{p, q, \lambda}$, Ann. Funct. Anal. 2, 1 (2011), 72-83.

[9] J. TIAN, X.-M. HU, A new reversed version of a generalized sharp Hölder's inequality and its Applications, Abstr. Appl. Anal. 2013, (2013), Article ID 901824, 9 pages.

[10] J.-F. TIAn, Extension of Hu Ke's inequality and its applications, J. Inequal. Appl. 2011, (2011), 77.

[11] J.-F. TIAn, Property of a Hölder-type inequality and its application, Math. Inequal. Appl. 16, 3 (2013), 831-841.

[12] J.-F. Tian, Properties of generalized Hölder's inequalities, J. Math. Inequal. 9, 2 (2015), 473-480.

[13] S. WU, Generalization of a sharp Hölder's inequality and its application, J. Math. Anal. Appl. 332, (2007), 741-750. 